\title{
Contributos do Processo de Metareciclagem de Máquinas Caça-Níqueis para Contextos Sócio Educacionais
}

\section{Cristina Paludo Santos, Alexandre dos Santos Roque, Guilherme Schievelbein, Tiago Brum, Vinicius Zuse}

\author{
Universidade Regional Integrada do Alto Uruguai e das Missões (URI) \\ 98.802-470 - Santo Ângelo - RS - Brasil \\ paludo@santoangelo.uri.br, roquedsantoangelo.uri.br, \\ guilhermeschievelbein@gmail.com, tiagobrum@hotmail.com, \\ vinizuse@gmailo.com
}

\begin{abstract}
This paper presents the experience of reuse of slot machines in favor of Education. The actions involve the various steps of the metarecycling process for the reuse of components and styling of new devices and the development of computer applications that include pedagogical content. Case studies were developed in schools in order to evaluate the reflexes represented by the installation and use of the modified technologies. Among the results, we highlight the dissemination of technological waste reuse culture, stimulating sustainable attitudes, proliferating and multiplying the resources and applications resulting from them.
\end{abstract}

Resumo - Este artigo apresenta um relato de experiência do reaproveitamento de máquinas caça-níqueis em prol da Educação. As ações desenvolvidas envolveram a execução das etapas provenientes do processo de metareciclagem com vistas ao reuso de componentes e estilização de novos artefatos e o desenvolvimento de aplicações computacionais que contemplam conteúdos pedagógicos. Estudos de casos foram realizados em escolas com vistas a avaliar os reflexos representados pela instalação e utilização das tecnologias modificadas. Dentre os resultados obtidos destaca-se a disseminação da cultura do reuso de lixo tecnológico estimulando atitudes sustentáveis, proliferando e multiplicando os recursos e aplicações delas decorrentes.

\section{Introdução}

$\mathrm{Na}$ sociedade contemporânea, busca-se novas construções paradigmáticas com concepções educacionais mais voltadas à sustentabilidade, onde os seres humanos possam interagir com a natureza desde o princípio de sua educação, aprendendo a respeitá-la. Neste novo paradigma os pressupostos da ecopedagogia e educação ambiental assumem um importante papel instigando reflexões e ações na busca por soluções para os problemas gerados pelo homem ao meio ambiente [Halal 2015].

Dentre as ações que marcam a relação do homem com a natureza insere-se a geração desenfreada de resíduos eletroeletrônicos, decorrente da acelerada revolução tecnológica que produz inúmeros equipamentos em larga escala com variadas utilidades. Se por um lado esses equipamentos surgem com o intuito de proporcionar conforto, praticidade, lazer e entretenimento, por outro vem acarretando grandes 
alterações no meio ambiente, transformando um ecossistema antes simples de interações químicas, físicas e biológicas em sistemas muito mais complexos.

Imerso neste cenário, o presente trabalho propõe caminhos possíveis que afirmam na prática o comprometimento com os princípios ecopedagógicos por meio do processo de metareciclagem de resíduos eletroeletrônicos, mais especificamente de máquinas caça-níqueis. A disseminação indevida de tais máquinas, bem com os malefícios sociais causados pela mesma, determinou a criação da lei de proibição dos caça-níqueis no Brasil. Por um lado, as leis surgem para proibir o uso de tais máquinas para proteger a sociedade dos vícios causados por tais equipamentos, mas, por outro lado, geram um problema na medida em que não prevê a destinação adequada das máquinas apreendidas. Com a chegada de novas leis e o não cumprimento das mesmas, milhares de máquinas são apreendidas e acumuladas em depósitos.

Como forma de minimizar os impactos causados pelo problema de descarte indevido emergem várias iniciativas de instituições de ensino e ONGs envolvendo o reaproveitamento dos componentes eletrônicos retirados das máquinas caça-níqueis. As iniciativas permeiam diferentes abordagens que incluem o reuso do material externo das máquinas para construção de móveis destinados para escolas e creches, reuso do hardware para montagem de laboratórios de informática, reuso das máquinas com vistas a transformá-las em totens de consulta à internet de utilidade pública, dentre outros [Oliveira 2013][Bortoluzzi 2012].

Assim, num ecossistema de ideias livres, baseado na crença de que o renascimento dos resíduos eletroeletrônicos em um cenário de educação, cidadania e proteção ao meio-ambiente é possível, são propostas ações com foco na readequação de máquinas caça-níqueis transformando-as em soluções para fins educacionais. Trata-se da subversão dos usos e funções da tecnologia, por meio de uma apreensão alternativa, tornando a tecnologia da informação veículo da cidadania e não do consumo.

A partir dessa iniciativa, busca-se integrar conhecimentos, aptidões, valores, atitudes e ações, convertendo-as em experiências educativas em prol de uma sociedade sustentável. Assim, o projeto parte da tecnologia, porém vai além de si mesmo constituindo-se em uma experiência singular, que põe as novas TICs a serviço das dimensões educacionais e sociais.

No intuito de melhor descrever as ações desenvolvidas o presente artigo estrutura-se conforme segue: a seção 2 apresenta os procedimentos metodológicos envolvidos no desenvolvimento dos artefatos propostos; a seção 3 apresenta as soluções propostas bem como apresenta as próximas atividades a serem contempladas como continuidade do projeto; a Seção 4 apresenta os estudos de casos práticos desenvolvidos em escolas com vistas a avaliar as soluções propostas e subsidiar uma análise criteriosa a respeito da necessidade do estabelecimento de ajustes nas ações futuras do projeto. Por fim, a Seção 5 apresenta as considerações finais.

\section{Procedimentos Metodológicos}

Sedimentado em uma abordagem pragmática, o projeto aborda o conceito do efeito prático e benéfico que o processo de meta-reciclagem de máquinas caça-níqueis possa ser capaz de gerar para a solução de problemas. Essa abordagem possibilita dimensionar a utilização de lixo tecnológico para reconstrução de novas tecnologias com o 
V Congresso Brasileiro de Informática na Educação (CBIE 2016)

Anais do XXII Workshop de Informática na Escola (WIE 2016)

aproveitamento de seus componentes, proporcionando a concepção de novas ideias e conhecimentos.

Fundamentado na convicção de que o uso das TICs não é um fim, mas sim um meio para facilitar o desenvolvimento das diversas capacidades dos indivíduos, gerando benefícios reais para a sociedade, o projeto visa o estabelecimento de ações programáticas que se direcionam a atuar no cotidiano escolar provocando situações de aprendizagem que promovam experiências e significados e contribuam para a formação de atitudes ecológicas sensíveis à identificação dos problemas e conflitos que afetam o ambiente em que vivemos.

No escopo do presente trabalho, o recebimento das máquinas caça-níqueis é formalizado por meio de um convênio firmado entre o Ministério Público do Rio Grande do Sul e a instituição executora sendo que o principal objetivo do acordo é assegurar uma destinação ambiental adequada às máquinas apreendidas, com aproveitamento dos componentes, transformando-as em estações de produção de conhecimento. Sendo assim, metodologicamente, as ações incluem desde a execução do processo de metareciclagem até o desenvolvimento de soluções com propostas pedagógicas.

$\mathrm{O}$ processo de metareciclagem agrega em si as etapas de triagem dos componentes eletrônicos; desmontagem das máquinas; separação dos componentes, avaliações sobre o funcionamento dos equipamentos; descaracterização da aparência externa das máquinas e montagem e configuração dos componentes eletrônicos reutilizáveis. Uma visão geral das etapas envolvidas no processo é apresentada na Figura 1.

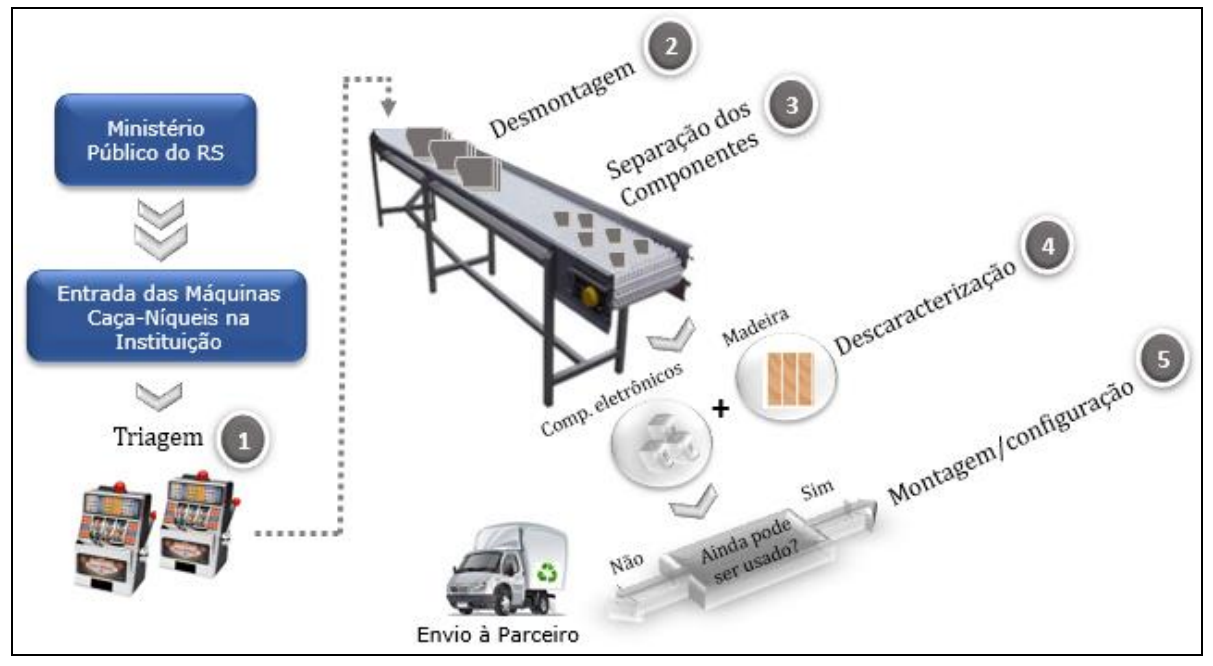

Figura 1. Visão geral do processo de Meta-Reciclagem

As etapas de triagem (1), desmontagem (2) e separação (3) resultam na madeira e nos componentes eletrônicos provenientes das máquinas. Os componentes eletrônicos são testados e avaliados e, no caso de não apresentarem condições de uso, são enviados a uma instituição parceira responsável pelo tratamento e destinação adequada dos mesmos. Os componentes passíveis de utilização são reaproveitados na construção do novo artefato (5). 
Já, a etapa de descaracterização (4) compreende o reuso da madeira proveniente das máquinas para a estilização do layout dos novos artefatos. Para a readequação das máquinas foram levados em consideração conceitos advindos da ergonomia que é a ciência que aplica teoria, princípios, dados e métodos para projetar de modo a otimizar o bem-estar humano, e da antropometria que estuda as medidas do corpo humano, visando adaptar as novas máquinas para o público ao qual se destinam. Dentre as normas ergonômicas consideradas no projeto cita-se a NBR ISO 9241-11:2011 que dispõem sobre medidas ergonômicas, onde a largura da cadeira de rodas é de 60 a $70 \mathrm{~cm}$, a altura das pernas varia entre 49 a $53 \mathrm{~cm}$, e a altura do encosto para os braços das cadeiras, deixando os botões das máquinas em uma altura confortável, que varia entre 92 a $96 \mathrm{~cm}$.

Além disso, consideram-se também as cores vivas, cromáticas, que despertam o interesse das crianças, com suas respectivas funções: Vermelho: coragem, energia, ação; Amarelo: euforia, originalidade, idealismo; Verde: bem-estar, saúde, paz coragem; e Azul: verdade, paz, fidelidade [Meyer 2014]. Neste cenário, o projeto apresenta-se também como uma experiência inovadora que põe os preceitos da arquitetura a serviço das dimensões sociais buscando estabelecer um diálogo com a comunidade e suas necessidades, já que a arquitetura procura adaptar o espaço projetado às necessidades humanas, tanto a nível fisiológico quanto a nível psicológico.

É importante salientar que as máquinas foram modeladas de forma temática, ou seja, cada máquina é estilizada de maneira a remeter a ideia do tema em relação a aplicação pedagógica para a qual foi projetada. Assim, para o software de matemática criou-se um layout externo de cubos, imitando dados. Já, para o software de reciclagem, criou-se um projeto que apresenta a máquina como uma grande lixeira, e assim por diante. A Figura 2 apresenta alguns registros da etapa de descaracterização sendo destacada a imagem da máquina original e o resultado após a estilização.

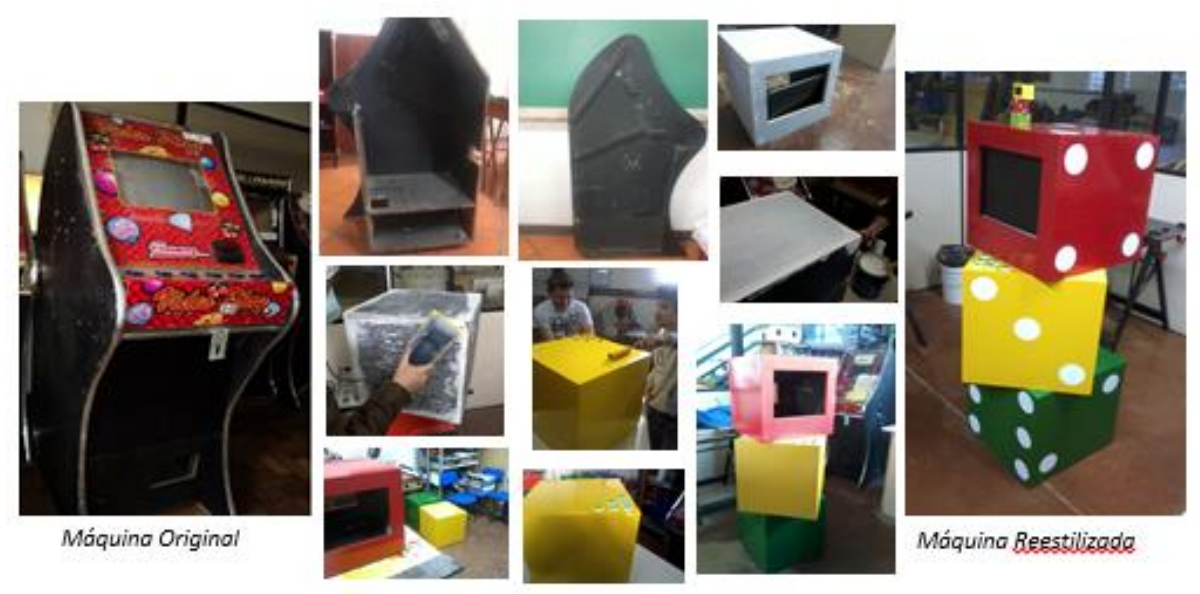

Figura 2. Processo de reestilização do layout externo das máquinas

Em paralelo ao processo de metareciclagem foram projetadas e implementadas as aplicações a serem instaladas nos novos artefatos concebidos. Todas as aplicações desenvolvidas são de cunho educacional e visam apoiar o processo de ensino na medida em que são utilizadas não somente para fins de entretenimento, mas agregam em si conteúdos educativos que podem estimular os aprendizes a consolidar conceitos já vistos na sala de aula [Abreu 2012]. 
As aplicações destinam-se ao público infantil, contemplando conteúdos do ensino fundamental. Foram desenvolvidas nas linguagens de programação JAVA e C\# e em todas as soluções propostas a interação se dá através dos botões presentes nas máquinas caça-níqueis originais, não havendo o uso de dispositivos apontadores e teclados. Além disso, princípios de usabilidade propostos por Nielsen (2004) foram considerados durante o projeto das mesmas, visando à facilidade de uso e de aprendizagem.

Outra propriedade relevante incorporada no desenvolvimento das aplicações é o suporte a recursos de acessibilidade permitindo que as mesmas possam ser utilizadas na maior extensão possível [Meyer 2014][Melo e Baranauskas 2006]. Em todas as aplicações fez-se uso dos recursos de jogos, visto que podem facilitar o processo de ensino-aprendizagem e ainda serem prazerosos, interessantes e desafiantes. Segundo Grübel e Bez (2006) o jogo pode ser um ótimo recurso didático ou estratégia de ensino e também ser um rico instrumento para a construção do conhecimento.

A Figura 3 apresenta algumas aplicações desenvolvidas, bem como os aspectos considerados no projeto e concepção das mesmas.

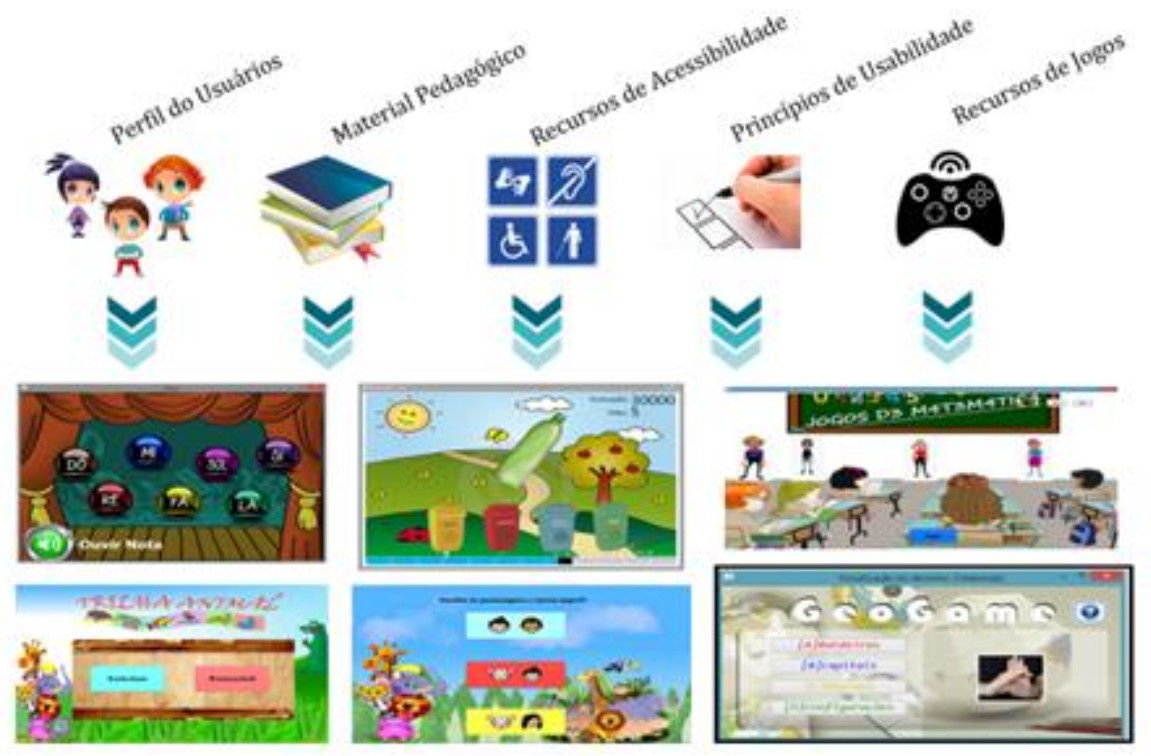

Figura 3. Aspectos considerados na produção dos Softwares Educacionais

O software Reciclar, por exemplo, usa o lúdico com o intuito de estimular a educação ambiental por meio da coleta seletiva do lixo, instigando o aprendiz à percepção da importância da cultura de preservação do meio-ambiente. Nele são implementados recursos de voz que permitem a interação por pessoas com deficiência visual. Já, o software GeoGame aborda questões relacionadas ao estudo das diferentes regiões do Brasil, excitando no aprendiz a curiosidade pela apropriação do conhecimento relacionado ao nosso país. Utiliza a tradução em libras para viabilizar o acesso a pessoas com deficiência auditiva. Além disso, existem softwares desenvolvidos para exercício das operações matemáticas, identificação de notas musicais, identificação do canto dos pássaros, identificação de pontos turísticos/históricos da região missioneira, identificação de espécies, dentre outros. Em todas as aplicações propostas existem recursos de acessibilidade incorporados como, por exemplo, áudio-descrição, tradução em libras, contraste de cores, ampliação de fonte e outros. 
V Congresso Brasileiro de Informática na Educação (CBIE 2016)

Anais do XXII Workshop de Informática na Escola (WIE 2016)

\section{Resultados e Discussões}

Diante do estabelecimento do projeto destaca-se a importância da disponibilização da tecnologia modificada, com interface mediadora entre aprendizes e máquina para escolas a fim de estabelecer novos parâmetros para a continuidade das ações propostas e, também, disseminar a tecnologia concebida incentivando outras organizações no desenvolvimento de ações que promovam, por meio da meta-reciclagem de lixo eletrônico, a inclusão digital e a proteção ao meio-ambiente. Assim, aprendizes e educadores assumem um papel fundamental e indispensável na avaliação das ações do projeto.

Desta maneira, um estudo de caso foi realizado para permitir uma avaliação sobre os reflexos representados pela instalação e utilização das máquinas nas escolas. Para isso, contou-se com a colaboração de escolas públicas e privadas do município. A Figura 4 apresenta registros da disponibilização das máquinas nas escolas.

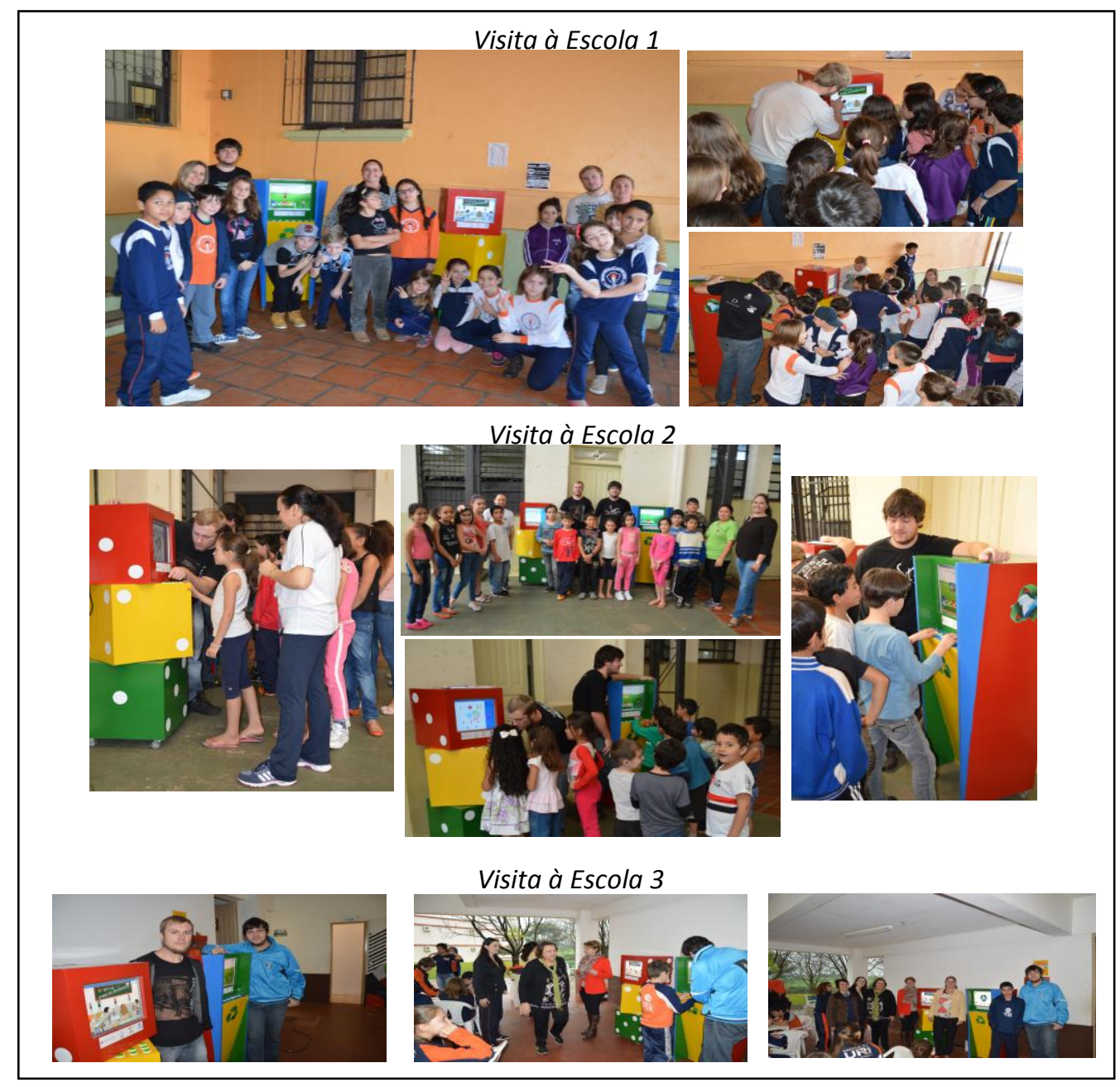

Figura 4. Registros das visitas realizadas às escolas colaboradoras

O processo avaliativo envolveu um total de 236 aprendizes do ensino fundamental. $\mathrm{O}$ uso dos artefatos produzidos, incluindo hardware e software, pelo usuário final promove as condições necessárias para que sejam realizadas avaliações envolvendo os fatores de qualidade estabelecidos por Vieira (2014), tais como, 
legibilidade (avalia a possibilidade de diferentes pessoas entenderem a aplicação); manipulabilidade (avalia a possibilidade de diferentes pessoas manipularem a aplicação com facilidade); utilizabilidade (avalia a conveniência e a viabilidade de sua utilização ao longo do tempo); validabilidade (avalia se a aplicação executa as funções para as quais foi projetada) e, fidedignidade (avalia a correspondência da aplicação com às necessidades identificadas).

Os fatores de qualidade determinam a qualidade do ponto de vista dos usuários da aplicação. A Figura 5 apresenta os registros da execução do processo avaliativo, sendo observada a interação dos aprendizes com os softwares produzidos, bem como analisados os aspectos ergonômicos considerados na readequação das máquinas.

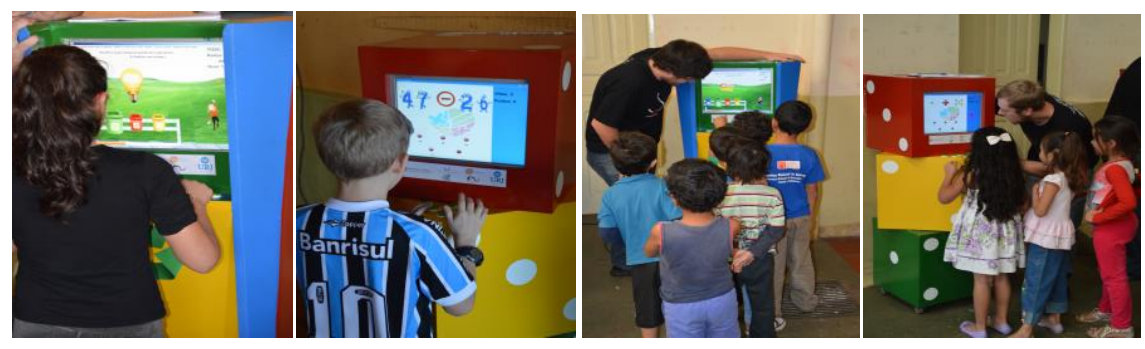

Figura 5. Utilização das máquinas por aprendizes

Para cada um dos fatores foram definidos critérios que comportam-se como atributos primitivos passíveis de serem avaliados, tais como: (1) Gosto pelo uso de jogos educativos; (2) Facilidade de uso; (3) Facilidade de percepção de conteúdos não textuais; (4) Facilidade de interação com os recursos de acessibilidade; (5) Nível de dificuldade das tarefas; (6) Aquisição de conhecimento através do uso das ferramentas pedagógicas; (7) Satisfação do usuário.

Para identificar as percepções dos usuários quanto aos critérios avaliativos foram considerados valores pontuais que variam de 1 a 3 , coletados a partir de um instrumento elaborado para guiar o processo. As respostas de cada critério foram compiladas através da média da pontuação de cada instrumento, sendo que 1 ponto equivale a resposta afirmativa, 2 resposta parcial e 3 a uma negação.

A partir dos resultados obtidos constatou-se que a grande maioria as crianças apresentaram grande interesse em utilizar os jogos educativos (questão 1) e tiveram facilidade na interação com os jogos propostos (questões 2, 3 e 7). Quanto a aceitação em relação aos recursos assistivos disponíveis nas aplicações (questão 4), todos concordam que é importante prover possibilidades para que pessoas com deficiência possam também utilizar as aplicações, mas algumas observações foram feitas que apontaram a necessidade de alguns ajustes em relação aos dispositivos de áudio utilizados nas máquinas. Dentre elas destaca-se o apontamento realizado por um dos aprendizes que diz "tem muito barulho aqui e não consigo escutar o som. Tem como aumentar o volume?" (aprendiz R.A. 07 anos). Realmente, o ruído do ambiente impedia que o som fosse audível o suficiente, o que induz a necessidade de ajustes no que se refere a esta funcionalidade. No que se refere às questões 5 e 6 , relacionadas ao nível de dificuldade das tarefas, bem como ao aprendizado a partir da aplicação proposta, foi possível averiguar que as crianças apesar se encontrarem certas dificuldades na resolução das questões, conseguiram realizar as tarefas em ambos os softwares. A 
V Congresso Brasileiro de Informática na Educação (CBIE 2016)

Anais do XXII Workshop de Informática na Escola (WIE 2016)

Figura 6 apresenta a compilação dos resultados obtidos no processo avaliativo envolvendo as três escolas participantes.

O processo também envolveu a participação de 10 educadores que foram instigados a utilizar as soluções propostas e após relatar as suas constatações sobre o ambiente. Para guiar a avaliação em relação às propostas apresentadas, foram considerados os seguintes critérios: (i) Coerência na apresentação do conteúdo; (ii) Adequação dos recursos de interatividade; (iii) Possibilidade do uso das aplicações sem a presença de um instrutor; (iv) Adequação do nível de dificuldades das questões propostas ao público para a qual se destina; (v) Adequação dos recursos de acessibilidade disponibilizados nas aplicações; (vi) Contribuição para o processo de aprendizagem; (vii) Limitações das soluções propostas.
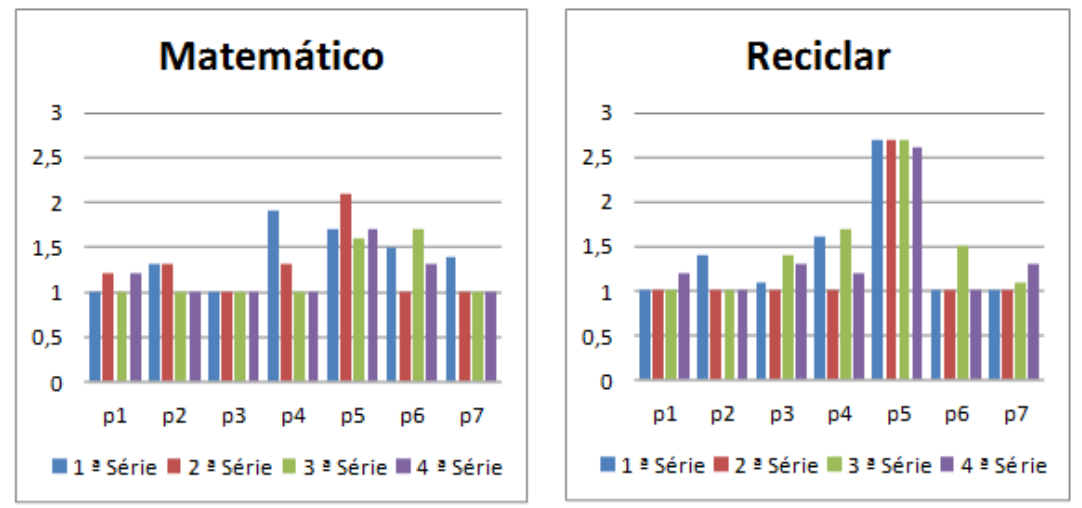

Figura 6. Resultados obtidos do processo avaliativo realizado por aprendizes

A partir destes critérios foi possível constatar a satisfação dos educadores em relação à proposta do projeto. Todos foram unânimes em afirmar que o projeto provoca grande entusiasmo nos aprendizes para a realização das atividades pedagógicas providas pelo ambiente. Outros apontamentos feitos pelos educadores e que contribuíram para o direcionamento de ações futuras foram:

"Fiquei impressionada com a transformação das máquinas. Acho que vocês deveriam colocar uma foto de como a máquina era e no que ela se transformou. Isso conscientiza os alunos de que lixo pode ser transformado em algo útil e que promove benefícios ao meio-ambiente. Quanto às aplicações estão muito bem elaboradas, envolvem conteúdos para as faixas etárias que se propõem e possuem uma interface lúdica que chama a atenção das crianças. Assim, ao mesmo tempo que elas jogam (o que adoram fazer), estão consolidando os conhecimentos já adquiridos em sala de aula." (M.T.S., 35 anos)

"Muito interessante e diferente a proposta. Mostra aos alunos como o que era usado para o crime foi transformado em algo útil para a sociedade. Os jogos são fáceis de usar e disponibilizam conteúdos que estão de acordo com o que é ensinado nas séries iniciais. $O$ que me chamou atenção foi a possibilidade de crianças cegas poderem utilizar as aplicações. Mas, fica uma sugestão para que seja possível configurar o volume do áudio, pois como as máquinas devem ficar no pátio da escola, o barulho muitas vezes impede a escuta do som. Quanto a áudio-descrição, a mesma está muito boa. Fica fácil de uma criança com deficiência visual entender o que deve ser 
V Congresso Brasileiro de Informática na Educação (CBIE 2016)

Anais do XXII Workshop de Informática na Escola (WIE 2016)

realizado. A inclusão do braile nos botões também está adequada para a interação." (A.H.D, 42 anos)

Tais apontamentos nos incentivam a continuar e realizar novos estudos que subsidiem a implementação das ações futuras. Acredita-se que a proposta deste trabalho faz dele um importante instrumento de incentivo ao crescimento de novas iniciativas, inspirando outros setores da sociedade a participarem do processo de metareciclagem. Além disso, projetos inseridos neste contexto apresentam-se como uma valiosa ferramenta, contribuindo fortemente para propiciar o desenvolvimento sustentavél.

\section{Conclusões}

Entende-se que o conceito de desenvolvimento sustentável, visto de forma crítica, tem um componente educativo formidável: (1) a preservação do meio ambiente depende de uma consciência ecológica e, (2) a formação da consciência depende da educação. Desta forma, este trabalho surge como uma iniciativa instigadora de novas ideias, voltada para criação de saberes e conhecimentos relacionados ao desenvolvimento e uso de recursos computacionais (hardware e software), procurando provocar mudanças, mesmo que tímidas, na formação de atitudes voltadas para a preservação do meio ambiente na comunidade escolar.

Como principais resultados observados citam-se os esforços no desenvolvimento das várias etapas envolvidas na concepção dos artefatos, conduzidos por uma equipe multidisciplinar, engajada e articulada com os objetivos do trabalho, concebida com vistas a contemplar a infraestrutura humana adequada para o desenvolvimento das ações propostas. Tal equipe, composta por pesquisadores das áreas de psicologia, matemática, biologia, computação e arquitetura, favoreceu e amparou as discussões acerca dos aspectos pedagógicos, psíquicos, arquitetônicos e ambientais envolvidos no processo de meta-reciclagem.

Esta iniciativa também despertou ações pedagógicas nos ambientes escolares participantes que ampliaram e reforçaram a disseminação da cultura do uso racional dos recursos naturais, estimulando atitudes sustentáveis por meio da realização de trabalhos com reciclagem do lixo. Com isso, as ações ultrapassaram os limites previstos no escopo deste trabalho, despertando um processo reflexivo mais amplo.

Além disso, as ações desenvolvidas atraíram a atenção de muitas escolas da região e tiveram grande repercussão na sociedade, sendo conferido, no ano de 2014, os Prêmios Educação RS e Destaque em Extensão ao trabalho desenvolvido. O impacto positivo demonstra o compromisso em fortalecer as bases da cidadania, intensificar a dinâmica de ações em favor do meio ambiente, proporcionar momentos de discussão e de envolvimento da comunidade escolar e promover, por mais tímidos que pareçam, progressos qualitativos na educação para o desenvolvimento sustentável.

As contribuições vislumbradas com a realização deste trabalho podem ser descritas de acordo com os impactos causados em diferentes contextos. No contexto ambiental por favorecer o meio ambiente através do reuso de componentes que, se descartados de forma indevida, poderiam causar danos à natureza e à saúde; em âmbito social por promover a inovação sustentável e proporcionar formas diferenciadas de apoio ao ensino; no contexto acadêmico por incentivar o desenvolvimento de novos trabalhos envolvendo a reciclagem de componentes eletrônicos com foco na educação e, 
no contexto regional por caracterizar-se como uma experiência inovadora na região de abrangência, que poderá servir de incentivo para que outras instituições atentem para os benefícios do processo de meta-reciclagem.

É importante mencionar que, apesar de já existirem outros projetos que desenvolvam ações para o reaproveitamento de lixo eletrônico, eles distinguem-se do presente trabalho uma vez que, em sua maioria, atuam na reutilização das máquinas para construção de móveis e/ou montagem de computadores para equipar laboratórios de informática nas escolas públicas. A partir disso, pode-se afirmar que este trabalho desenvolve ações inovadoras que aplicam a computação em prol da área da educação e ajudam a promover o desenvolvimento da sociedade.

\section{Agradecimentos}

Nossos agradecimentos especiais ao Ministério Público do Estado do Rio Grande do Sul pela concessão das máquinas caça-níqueis e pelo aporte financeiro concedido às pesquisas desenvolvidas no âmbito do projeto.

\section{Referências Bibliográficas}

Abreu, Flávio, et al. (2012) "Métodos, Técnicas e Ferramentas para o Desenvolvimento de Software Educacional: Um Mapeamento Sistemático."Anais do $23^{\circ}$ Simpósio Brasileiro de Informática na Educação, ISSN (2012): 2316-6533.

Bortoluzzi, Fabrício, et al. (2012) "Projeto Lótus: Um Relato da Transformação de Máquinas Caça-Níqueis em Computadores de Apoio ao Ensino Fundamental." Anais do Workshop de Informática na Escola. Vol. 1. No. 1. 2012.

Grübel, Joceline Mausolff; Bez, Marta Rosecler. (2006) "Jogos educativos." RENOTE 4.2.

Halal, Christine Yates. (2015) "Ecopedagogia: uma nova educação." Revista de Educação 12.14.

Melo, Amanda Meincke, and M. Cecília C. Baranauskas. (2006) "Design para a inclusão: desafios e proposta." Proceedings of VII Brazilian symposium on Human factors in computing systems. ACM.

Meyer, Anne; ROSE, David H.; GODON, David. (2014) Universal Design for Learning - Theory and Practice. Wakefield MA: CAST.

Nielsen, J. (2004) Usability inspection methods. In: Proceedings of Conference Companion on Human Factors in Computing Systems. pp. 413-414.

Oliveira, Alyson Rodrigo, et al. (2013) "Educação Ambiental no Contexto Tecnológico: criação de um fliperama utilizando lixo eletrônico." Proceedings of Safety, Health and Environment World Congress. Vol. 13.

Vieira, Fábia Magali Santos. (2014) Avaliação de Software Educativo: Reflexões para uma Análise Criteriosa. Disponível em: www.edutec.net/edmagali2.htm. Acesso em: 11 abr. 2014. 